\title{
INCÊNDIO EM HOSPITAL DE GRANDE PORTE: ATUAC̣ÃO DO SUPERVISOR DE ENFERMAGEM
}

Walter Fernandes*

\begin{abstract}
RESUMO - Relata o acontecimento de um incêndio em um hospital geral e discorre sobre a experiência de um supervisor de enfermagem que trabalha à noite. Aponta dois problemas cruciais: total despreparo de pessoal e de material para dar atendimento neste tipo de situação e ausência, no turno da noite, de apoio e técnico administrativo que concorram para o desempenho da enfermagem.

ABSTRACT - This work reports the events of a fire in a general hospital and describes the experience of a nursing supervisor working during the night. It points out two crucial problems: total lack of personel training, material for assistance in such type of situation and, in the night shift, technical and administrative support to help make a good nursing performance possible.
\end{abstract}

\section{INTRODUC̣ÃO}

Os hospitais e outros serviços de saúde desfrutam de uma posição única e invejável na comunidade. 0 povo respeita e preza, instintivamente, esses estabelecimentos, pela própria natureza de suas atividades. É também singular por suas características físicas. Na realidade, é constituído por muitas empresas reunidas em uma só, formando uma verdadeira cidade. É, sobretudo, um centro de serviços de saúde, mas também, é, em parte, hotel, laboratório, farmácia, sala de reuniões, biblioteca, capela, lojinha de livros e local de ginástica. Além do corpo clínico, sua força de trabalho inclui uma ampla e significativa amostra de pessoal de apoio.

Com toda essa complexidade o hospital tem como função principal os cuidados de saúde, e um requisito básico é que esses cuidados sejam desempenhados com a maior perfeição. 0 diagnóstico competente, a terapia apropriada, a proteção constante do paciente são os seus elementos mais importantes. Além do mais, o hospital deve ser um lugar seguro, não só para os doentes, como para os visitantes e empregados. O hospital que não zelar pela segurança total daqueles que o utilizam estará trabalhando contra a própria razão de sua existência.

É, realmente incompatível com sua função que um estabelecimento, destinado unicamente a promover 0 bem estar do homem, possa, as vezes, contribuir para seu sofrimento, seja por um ato impensado, seja em virtude de condições pouco seguras.

O fato se torna mais grave, pois, qualquer negligência pode ter consequências sinistras. 0 menor dano é a perda financeiramente mensurável. Mas pode também causar danos ao paciente. A maior preocupação, entretanto, é a possibilidade de causar lesões permanentes ou a morte a um ou mais seres humanos.

Diante disso, torna-se evidente a urgência de um programa destinado, especificamente, a reduzir ao mínimo possível a gravidade e as consequências de um incêndio em hospital.

0 leitor, mais familiarizado com a prática, o ensino ou a pesquisa em enfermagem estará curioso em saber por que diante de tantos temas nos propomos a tratar deste. É que, por sua essência, a segurança hospitalar desperta em todos os profissionais da saúde algum envolvimento. Ousamos até afirmar que todo aquele que de alguma forma vir a tomar conhecimento dessa narrativa será levado à reflexão, pelo menos, de como e qual seria a sua participação num evento dessa natureza.

\section{O LOCAL DO INCÊNDIO}

Para nos fazer melhor entender, passamos a descrever o local em que ocorreu o incêndio. Um hospital

\footnotetext{
${ }^{*}$ Enfermeiro.
} 
de grande porte, na Zona Norte da Cidade do Rio de Janeiro em prédio monobloco de 14 andares. Em seu interior, na parte assistencial encontramos: vinte e três clínicas, cinco serviços de terapia intensiva, centro obstétrico, berçário, centro cirúrgico e central de material. Em média setecentos e cinquenta pacientes. Deste total temos: dez por cento em condições críticas e outro tanto percentual considerados graves. A equipe multiprofissional no momento do sinistro tinha um quantitativo de vinte enfermeiros; setenta e cinco auxiliares de enfermagem; seis auxiliares operacionais. Entre médicos e acadêmicos de medicina poderíamos contar quarenta elementos. Se considerarmos os acompanhantes que não ultrapasavam quinze e mais dez pessoas para o pessoal encarregado de promover a limpeza, estávamos com uma população de novecentas pessoas, em média.

\section{INÍCIO}

Madrugada, 31 de março para $1^{0}$ de abril. Na central de material os autoclaves já estavam desligados. Porém as estufas atendiam às necessidades de um centro cirúrgico onde estavam sendo realizadas uma laparotomia exploradora, sob narcose e uma drenagem de tórax, com anestesia local. No centro obstétrico já estava registrado no Relatório Geral de Enfermagem dois partos normais. E, ao lado de outras oito puérperas, as mães mais recentes desfrutavam de um sono reparador. 0 nosso pequeno berçário abrigava dezesseis crianças. Ali, quatro prematuros eram compensados com o auxílio de hidratação venosa, oxigênio e o calor das incubadoras.

Continuando a minha descida, pois já descrevi três andares, no sentido de cima para baixo, chegamos ao Serviço de Terapia Intensiva. Neste serviço, dez pacientes. Oito em situação crítica, lutavam para sobreviver amparados por respiradores e medicamentos. Observados pelos gráficos registrados nos visores dos monitores e silenciosamente cuidados pela competência, carinho, calor e amor of erecido pelos enfermeiros, que computador algum poderá substituir.

Na outra parte do mesmo andar, dezesseis pacientes queimados ainda se lembrando do pavor destrutivo do fogo interrompiam seu agitado sono, ora com dores, ora com gritos de pavor provocados por pesadelos. No Centro de Tratamento de Queimados, a clientela é predominantemente infantil. Ali encontramos representantes da infância em todas as suas fases desde o lactente ao púbere. Um enfermeiro e três auxiliares de enfermagem promoviam o atendimento de suas necessidades humanas e terapêuticas.

Tornaria a leitura cansativa se nós descrevêssemos as condições de todos os pacientes das nossas vinte e três clínicas. Sendo assim, destacaremos a Pediatria, com trinta e seis crianças e a Unidade de Traumatologia com sessenta e oito pacientes. Entre os pacientes da ortopedia, destacamos oito que estavam com tra- ção trans-esquelética e quatro grandes gessados. Não poderíamos omitir a Clínica de Urologia pelas características especiais de seus pacientes. Em nosso hospital a clientela é predominantemente geriátrica e tínhamos entre eles, quatro em pós operatório imediato de prostatectomia com a tradicional e necessária irrigação contínua.

No andar que ocorreu a tragédia, especificamente na Clínica de Urologia, entre os doze internados, tínhamos três recebendo o tratamento de diálise peritonal. $\mathrm{Na}$ Unidade de Emergência, que estava funcionando naquele andar em caráter excepcional, porque o espaço que lhe é destinado estava em obras, tínhamos trinta e seis pacientes de ambos os sexos, adultos. Vinte nos repousos e dezesseis na grande emergência, onde, entre suturas, hidratações venosas, hemorragias digestivas e infarte agudo do miocárdio, tínhamos seis em coma profundo, quase todos por traumatismos crãneoencefálico, vítimas ativas e passivas do trãnsito violento e desordenado de nossa cidade.

\section{ATIVIDADES DO SUPERVISOR}

Neste cenário, três supervisores de enfermagem se revezam, um em cada noite, sem ter solicitado a alguém tamanha responsabilidade, feito algum concurso para o cargo, ou mesmo recebido algum preparo para as atividades que exercem. Esses enfermeiros praticam a arte de reunir as mais variadas correntes de psicologia, urbanidade, sociologia, legislação trabalhista, direito legal, perícia de enfermagem, amor ao próximo, e muita coragem para decidir sobre tarefas que dizem constituir a Supervisão em Enfermagem, só que os autores consultados, não afirmam isso.

$\mathrm{E}$, naquela madrugada, como não podia deixar de ser, eu estava de plantão. Às três horas, exatamente, o telefone tocou. Uma colega enfermeira, solicitava que eu fosse rápido ao seu setor, estava ocorrendo um incêndio. Considerando a data, ainda lhe indaguei. - Não tinha coisa melhor para primeiro de abril? Subi correndo.

Chegando ao local solicitado, a quantidade excessiva de fumaça não nos deixava divisar nada. Acionei a equipe que estava de plantão na emergência e pedi que ajudassem a retirar os pacientes. Na Nefrologia, os pacientes que estavam sendo dialisados já estavam em macas e o setor totalmente evacuado. Não conseguimos retirar as máquinas.

Entre mil problemas a serem resolvidos, considerei três prioritários: evacuar o andar; impedir o pãnico e evitar que o incêndio viesse a adquirir maiores proporções.

Tomei algumas providências. Desci à sala de supervisão, dei três telefonemas. Entre eles liguei para a enfermeira chefe, tal a gravidade do problema. Seu hospital está pegando fogo, lhe falei. Se fosse outra pessoa que telefonasse, eu diria que era $1^{\circ}$. de abril, ela 
respondeu. Consiga todo o auxílio que puder, eu vou agir. Encerrei o diálogo.

A precipitação, o pãnico se apoderaram daqueles que estavam diretamente envolvidos e que poderiam prestar muito auxílio. A falta de uma licença, uma diretriz a seguir e a falta de alguém com experiência em tragédia deste vulto, colaborou muito para a desordem que se instalou.

Desligaram a rede elétrica antes do tempo, pois tínhamos, no início mais fumaça que fogo. Tínhamos uma média de dez pessoas retirando pacientes da Unidade de Emergência. Só eu retirei cinco. Envolvido em lençol molhado, entrava e saia através da fumaça. No último paciente, ficamos preso pela fumaça e arrastei-o para a janela a fim de pegar um pouco de ar. Como ficamos com parte do corpo do lado de fora do prédio o grupo que assistia ao salvamento julgou que iríamos cair. Ele já estava em coma e eu quase asfixiado. Molhei bastante um lençól, envolvi o paciente e arrasteio em direção à saída. Quando rompemos a fumaça entreguei-o a outros funcionários que estavam do outro lado em melhores condições que eu.

Checamos a Unidade de Emergência. Em breve tempo tínhamos formado um esquadrão composto de dois auxiliares e três acadêmicos de medicina. Como não havia mais pacientes no setor, resolvemos combater o incêndio. Estava tudo muito direitinho. 0 local da mangueira, extintores além dos que já estavam sendo usados e o vidro escrito, com letras grandes e vermelhas, "INCÊNDIO".

Quebramos o vidro e retiramos a mangueira muito bem enrolada. Impregnado que sou pela enfermagem, imaginei as ataduras do Manual de Enfermagem da Dra. Elvira de Felice. Só que as ataduras fixavam e as mangueiras, contrariando o manual, se rompiam quando tentávamos manuseá-las. 0 resultado foi que a água saiu para todos os lados, menos em direção ao local do fogo.

Nesse momento, a brilhante corporação do Corpo de Bombeiros já havia chegado. Passei então a desenvolver meu trabalho direcionado à outra prioridade, que era impedir o pânico generalizado. Isto é, promover a evacuação dos pacientes com o menor número de atropelos possíveis.

Ao leitor, posso estar dando a impressão que só havia eu ou que o incêndio era todo para mim. Eu explico. A verdade é a seguinte: em nosso hospital, a partir das 16 horas, dois elementos assumem todas as responsabilidades, respeitando a hierarquia e as características dos problemas apresentados, o chefe da equipe médica de emergência e o supervisor de enfermagem. 0 chefe de equipe foi dominado pelo pãnico e ficòu com sua capacidade de decisão quase que abolida. Como não havíamos combinado nada com o poder destrutivo do fogo, ele continuava fazendo estragos e, possívelmente vítimas. Por necessidade, assumi o comando das ações.

Avaliei a capacidade de ação dos bombeiros dian- te do volume do fogo. Vi segurança nas ações, roguei a DEUS e subi. Clínica por clínica, ajudava a colocar pacientes em macas, oferecia uma palavra de esperança e conforto. Aos mais tranqüilos eu dizia que não precisava fugir, pois o fogo seria logo dominado. Era difícil. Com o medo e o pavor do fogo aproximadamente sessenta por cento da equipe tinha desertado. Alguns salvando apenas a sua pele. Outros levavam consigo grupo de pacientes. Não lhes tiro a razão. Era preciso ter uma causa muito superior para romper novamente a barreira de fumaça que se instalou no segundo, terceiro e quarto andares.

No décimo andar, uma médica, não gostou quando pedi a um grupo de gestantes e puérperas que não descessem. Grosseiramente eu lhe falei. - Se ouvesse algum perigo eu estaria aqui? Foi o único momento que perdi a calma. Agi assim porque a escada estava totalmente congestionada. Os pacientes gessados cairam nas escadas e foi um "sufoco" para salvá-los do pisoteamento. A tragédia teria assumido maiores proporções se resolvessem descer todos os pacientes de uma só vez, principalmente se considerarmos as patologias e as diferentes faixas etárias.

Poder e capacidade de decisão, características de um supervisor. Quanta teoria e que distãncia da realidade! Pensando assim, entrei no Serviço de Terapia Intensiva. Ali, a equipe de saúde, isto é, o que restava. Muitos com o pavor desertaram. Os que permaneceram, ventilavam os pacientes uma vez que a maioria dos respiradores foram desligados, eram elétricos.

Chegamos juntos ao Serviço de Terapia Intensiva eu e o Tenente do Corpo de Bombeiros. Já havíamos tido uma alteração no $2^{\circ}$. andar, pois um de seus soldados estava abrindo uma porta com machadinha e o que faltava era apenas soltar o trinco. Mas, voltamos ao S.T.I.. A ordem técnica é evacuar todo o prédio, falou o oficial com toda a autoridade que lhe conferia o cargo e as condições. Como transportar dez pacientes nessas condições, alguns morrerão no caminho, ponderei. Ele me respondeu, a ordem é evacuar. Mais uma vez me lembrei dos Manuais de Enfermagem que nunca pude aplicar seus ensinamentos. Como se tratava de hospital e a ordem emanava de um manual, eu teria que decidir. Desobedeci. Se tentássemos retirar os pacientes, todos morreriam. Não temos elevadores mecânicos nem rampas. As macas leitos não descem degraus, o pessoal não agüentaria levar nos ombros. Descer nove andares era missão impossível. Assumi a responsabilidade, eu morreria com eles. Tínhamos mais chances ali que tentando salvá-los. Tinha fé em DEUS que o fogo seria dominado.

Fui à janela e olhei para baixo, outra tragédia. Como folhas de árvores os pacientes estavam deitados no jardim, aguardando o socorro que já havia chegado. Uma fila de ambulância procedente de hospitais do INAMPS, do Estado e do Município recolhiam os pacientes desordenadamente. Teriam mais problemas. Co- 
mo iriam dar conta se nâo sabíamos nem para onde estavam sendo levados?

Tenho a impressâo que voei. Fui do $9^{0}$ andar ao térreo em poucos minutos. Perdi apenas o nome dos pacientes que foram transportados em uma ambulância. Solicitei a uma auxiliar de enfermagem que relacionasse os pacientes que estavam sendo transportados, nome, destino e placa da ambulância.

Voltei ao foco do incêndio. Os soldados do Corpo de Bombeiros estavam levando nítida vantagem, desci ao pátio e pedi que parassem as rømoções. Dispensei as ambulâncias. Foi o meu grande atrito. Um médico de uma ambulância nâo gostou e perguntou quem eu era. Lhe falei que era enfermeiro. Então ele disse que não atenderia as minhas ordens e continuaria as remoções. Nesse momento, o chefe de equipe reapareceu, recuperado, fez a sua intervenção, dizendo que se responsabilizava pelos meus atos, quase enfartando o médico da ambulãncia.

Dia clareou e são lindas as manhãs de abril. A fumaça também já era pouca, alguns pacientes já retornavam aos leitos transportados por um elevador ligado à força de emergência. 0 diretor e todo o seu gabinete já estavam presentes. A reportagem escrita, falada e televisada tentava ouvir depoimentos. Tratei de verificar o estado físico e psicológico do pessoal de enfermagem. Deixei os repórteres para quem, de direito, os atendesse.

Esta experiência me leva a apontar algumas propostas, as quais poderão minimizar acontecimentos desta natureza.

Ao Serviço de Engennaria Hospitalar, propomos que os hospitais sejam dotados de:

- instalações elétricas que desliguem parte do prédio;

- elevadores manuais;

- mangueiras de fácil alcance e manuseio;

- alarme de incêndio;

- iluminação de emergência;

- depósito próprio para material combustível;

- locais próprios para fumantes; e

- capacitores para instalação de novos aparelhos elétricos.
Ao Serviço de Administração Hospitalar, propomos as medidas abaixo:

- formação de uma brigada ou equipe de emergência, entre os moradores da periferia;

- verificar quais os funcionários que deveriam participar voluntariamente da brigada;

- preparar o grupo da brigada, técnica e cientificamente para as funções de salvamento;

- fazer periodicamente exercício de incêndio simulado;

- testar com muita freqüência as condições externas do equipamento elétrico;

- manter as vasilhas de gases comprimidos, adequadamente tampadas e presas à parede;

- ter à mão o telefone e endereço da equipe da brigada, assim como do corpo administrativo;

- exigir que todo funcionário trabalhe identificado, bem como pacientes inconscientes e crianças.

\section{CONCLUSÃO}

Ao final deste relato, acreditamos ter despertado a consciência de que tal acontecimento, embora não desejado pode se tornar real. Nossa participação no sinistro foi tão técnica quanto emocional. Gostamos muito do hospital e da profissão que exercemos e não gostaríamos que enfermeiro algum passasse os terríveis momentos vividos naquela madrugada.

Entretanto, a nossa vontade não é lei e provavelmente mais sinistros ocorrerão. A nossa explanação não nos envaidece, ao contrário, nos deprime. Principalmente por saber que em muitos dos outros hospitais, se ocorrer um incêndio de grandes proporções, teremos muitas vítimas, pois as condições de segurança são idênticas ou piores.

De qualquer forma, a nossa narrativa resume uma trágica e emocionante experiência, a qual tentamos passar aos colegas. Nossas propostas, se avaliadas, poderão sofrer melhora técnica e outras poderão ser acrescentadas, mas a maior medida contra incêndio é evitar sua ocorrência. 